INTERNATIONAL DESIGN CONFERENCE - DESIGN 2018

https://doi.org/10.21278/idc.2018.0419

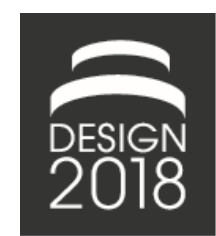

\title{
A PRODUCT PLANNING FRAMEWORK FOR MASS-CUSTOMISATION IN CONSTRUCTION
}

\author{
T. P. Y. Wee and M. Aurisicchio
}

\begin{abstract}
This paper provides a framework for modular product planning in construction. It integrates tools to support quality and flexibility in design. A case study was carried out on a chilled water modular plantroom. The Quality Functional Deployment (QFD) tool was effective at capturing and analysing the requirements from multiple disciplines. Modularisation was supported by the Dependency Structure Matrix (DSM), Modular Identification Matrix (MIM) and Generational Variance Indexes (GVI). The framework's novelty lies in tools integration to achieve mass-customisation for construction.
\end{abstract}

Keywords: product design, modularisation, mass customisation, case study, data driven design

\section{Introduction}

The construction industry makes up $6.5 \%$ of the UK economy (KPMG, 2016). In the last 20 years, the sector has "shown no productivity growth" (KPMG, 2016). Recently, the growing demand for sustainable high-value building products together with the needs for cost competitiveness and fast delivery are driving further industrialisation of the sector. Housing and labour shortage, increasing social expectations and strict government sustainability targets are also contributing to this development (Gann, 1996; Höök, 2006; Lawson et al., 2012; Marchesi et al., 2013). Offsite construction is a large contributor to the growth of the sector. Although offsite construction has already spread throughout the industry, its influence has been limited. The small to medium size prefabricated components currently used in construction have, in fact, little total value compared to the size of the whole industry. The UK Commission for Employment and Skills, for example, estimated that in 2013 the total market value for offsite construction was just $£ 6$ billion (i.e. 7\% of the total construction industry) (KPMG, 2016). Despite the current situation, there is great potential for off-site construction to gain more importance as " $70 \%$ of all construction projects can be conducted using offsite construction components" (KPMG, 2016).

Firms investing in off-site construction systems are targeting not just mass production but also masscustomisation. They want to develop building systems that can be made more adaptable to changing situations thereby reducing engineering risks, while addressing the needs of target customers and providing product variation. To achieve this, such firms have to invest more in product planning in the early phases of the construction process. In particular, they need to increase the quality and efficiency of the processes and the flexibility of the products. However, at present their approach to planning relies on the use of internal knowledge and expertise, rather than on consolidated and systematic methods, e.g. methods for requirement management and modularisation. While the benefits of planning methods are well accepted in other industries, their utilisation in the construction sector has been very limited. One reason is that each construction project is unique (Gilbert III et al., 
2013) and the sector tends to tackle engineering work focusing on solution development rather than problem understanding. Another reason is that previous research on requirements management and modularisation in construction has not been tested on advanced and industry-relevant case studies. Further, previous research work has not looked at offsite construction. The shift from building on site to off-site manufacturing operations provides a more favourable environment for the adoption of product planning methods (Jensen et al., 2014) in the early stages of the construction process (Veenstra et al., 2006; Marchesi et al., 2014).

This research aims at developing a framework for efficient, quality and flexible design of building systems delivered using off-site construction methods. The framework covers two interrelated elements: requirements management and modularisation. The novelty of the framework lies in the integration of tools to achieve efficiency and flexibility.

\section{Product planning frameworks}

There are many frameworks outside of construction that have been developed to support product planning. A subset of these is centred on modular product planning using techniques for requirement management, product architecture definition and modularisation, see Table 1. These frameworks often involve the application of QFD combined with a modularisation tool (Borjesson, 2010), e.g. Design Structure Matrix (DSM), Modularisation Identification Matrix (MIM), Coupling Index (CI) and Generational Variety Index (GVI). Other modularisation tools are the Functional Flow Block Diagram (Hölttä-Otto, 2005; Emmatty and Sarmah, 2012), the Design Structure Matrix (Hölttä-Otto, 2005; Ulrich and Eppinger, 2008), and Axiomatic Design (Marchesi and Ferrarato, 2015). Very few of these frameworks and tools have made their way into the construction industry, and this is often attributed to the limited readiness of the industry to adopting systematic tools. Only recently manufacturing capabilities have been changed to become more favourable to mass-customisation. Within the research undertaken in the construction sector, mass-customisation has been considered as a strategy for dealing with building modules development (Veenstra et al., 2006; Gilbert III et al., 2013; Jensen et al., 2014). This research has focused on data oriented modularisation methods. Specifically, it has looked at methods integrating modularisation with requirements management through Quality Function Deployment (QFD).

Table 1. Product planning frameworks

\begin{tabular}{|c|c|c|}
\hline Frameworks & Data types & Description \\
\hline $\begin{array}{l}\text { Extended implementation } \\
\text { structure matrixes (EISM) } \\
\text { (Sellgren and Andersson, } \\
\text { 2005) }\end{array}$ & $\begin{array}{l}\text { QFD } 1 \text { (CR-FR); } \\
\text { QFD } 2 \text { (FR-TS); } \\
\text { EISM }\end{array}$ & $\begin{array}{l}\text { Intended to bridge the 'hard' technical } \\
\text { requirements with 'soft' interactive requirements } \\
\text { (Borjesson, 2010). }\end{array}$ \\
\hline $\begin{array}{l}\text { Modular Functional } \\
\text { Deployment } \\
\text { (Erixon, 1996) }\end{array}$ & $\begin{array}{l}\text { QFD } 1 \text { (CR-PP); } \\
\text { QFD } 2 \text { (PP-TS); } \\
\text { Module identification } \\
\text { matrix (Modular drivers to } \\
\text { TS) }\end{array}$ & $\begin{array}{l}\text { CRs are decomposed into controllable PPs. TSs } \\
\text { with similar properties are grouped with strategic } \\
\text { intent into modules. } \\
\text { TSs are grouped by product property and module } \\
\text { driver. }\end{array}$ \\
\hline $\begin{array}{l}\text { Modular product platforms } \\
\text { through Generational } \\
\text { Variety Index (GVI) and } \\
\text { Coupling index (CI) } \\
\text { (Martin and Ishii, 2002; } \\
\text { Simpson et al., 2006) }\end{array}$ & $\begin{array}{l}\text { QFD } 1 \text { (CR-ER); } \\
\text { QFD } 2 \text { (ER-TS); } \\
\text { GVI; } \\
\text { CI }\end{array}$ & $\begin{array}{l}\text { QFD } 1 \text { and QFD } 2 \text { are used to map } \\
\text { interdependencies between CRs, ERs and TSs. } \\
\text { QFD } 2 \text { is used to generate GVI. } \\
\text { Coupling matrix is used to generate CI. } \\
\text { The components to develop a platform are grouped } \\
\text { based on GVI and CI. }\end{array}$ \\
\hline
\end{tabular}

Technical solutions $=$ TS; Customer requirements $=\mathrm{CR}$; Functional requirements $=$ FR; Engineering requirements $=\mathrm{ER}$; Product properties $=\mathrm{PP}$ 
Building on the work of Simpson et al. (2012) and Martin and Ishii (2002), Veenstra et al. proposed a modularisation method for a house building, which focuses on the development of product platforms using GVI. Customer requirements are captured in the rows of a QFD matrix and product modules in their columns (Veenstra et al., 2006). The work uses GVI together with CI to identify residential house features that could be turned into modules or platforms. The research emphasises that GVI and CI together allow developing a deeper understanding of external design forces. Modules and platforms are determined following the decision rules set by Martin and Ishii (2002). In particular, features with no or low GVI are turned into fully or partially standardised platforms, and features with no or low coupling indexes-supply (CI-S) are considered for full or partial modularisation. The method approaches platform design and modularisation by tackling product uncertainty and risks.

Gilbert applied QFD to temporary housing by mapping customer requirements in the rows of a QFD matrix and non-functional requirements, constraints and functional requirements in their columns (Gilbert III et al., 2014). Gilbert's earlier work dealt with modularisation of temporary modular buildings (Gilbert III et al., 2013). The work used axiomatic design and product platform design for the development of modules. The methodology suggests that modules can be identified by grouping the functional requirements and physical design parameters of a system. The methodology categorises modules into common modules and specialist modules. The essential function of buildings is captured by core modules, which basically acts as a studio module and additional required features are designated to the specialist modules.

Overall there is a shortage of studies in construction to develop and evaluate systematic methods for product planning including modularisation. Such shortage may be due to the fact that construction projects are traditionally bespoke and less perceptible to the adoption of systematic methods. The works of Veenstra et al. (2006) and Gilbert III et al. (2014) provide an insight into systematic modular and platform design in construction. Both studies show the benefits of applying systematic methods for design of modular construction products. However, the two studies have limitations in that they do not consider the full complexity of the requirements management and modularisation problem. In addition they look at modularisation but they are limited in the consideration of the wider industrial context. Further research and development of modularisation tools, based on a systematic approach and specifically for the construction industry, is needed.

\section{Methodology}

This research has proposed a framework for efficient, quality and flexible design of building systems. The framework was developed by undertaking empirical research to understand the practices of the collaborating company and conducting a case study. The methodology to develop the framework involved three research phases as described below.

\subsection{Understanding the current approach to designing modular systems}

At the start of the research design documents were examined and meetings were held with expert engineers at the collaborating company to determine the current approach to designing modular systems. In addition, the first author was involved in an internal initiative to explore the opportunity to introduce a product configurator as this is a key tool for the management of modular products. A model showing how a product configurator would be used to manage modular products under the business and operational requirements of the collaborating company was also developed. The data upon which the model is based was collected through three meetings with the collaborating company's plant-room design leader. This model was further enhanced and validated with a week secondment at the company during which the researcher was given a demonstration of the product configurator by three systems engineering consultants and two engineers from the collaborating company.

\subsection{Framework development}

Based on the understanding emerging from the previous phase, the requirements of a product planning framework were identified and a framework including tools for requirement management and modularisation was proposed. 


\subsection{Framework evaluation}

The framework was subsequently evaluated using: 1) a live case study of a chilled water modular plantroom product (see Figure 1);2) a workshop; and 3) interviews. The case study was used to produce models of the plant-room requirements and modularise its design, while the workshop and the interviews to gather feedback. At the time in which the research was conducted a design of the plant-room already existed in the collaborating company.

The QFD tool was applied using a reverse engineering approach to identify the plant-room requirements. Requirements information was extracted from technical documents, modelled in QFD and subsequently validated during the workshop. The details of this methodology can be found in Wee et al. (2017a).

The plant-room was modularised with the use of multiple tools (i.e. MIM, GVI, and DSM). Modularisation information was extracted from engineering documents (e.g. product schematics and manuals), as well as interviews with engineers who developed the plant-room. The methodology for the modularisation work is explained in details in Wee et al. (2017b).

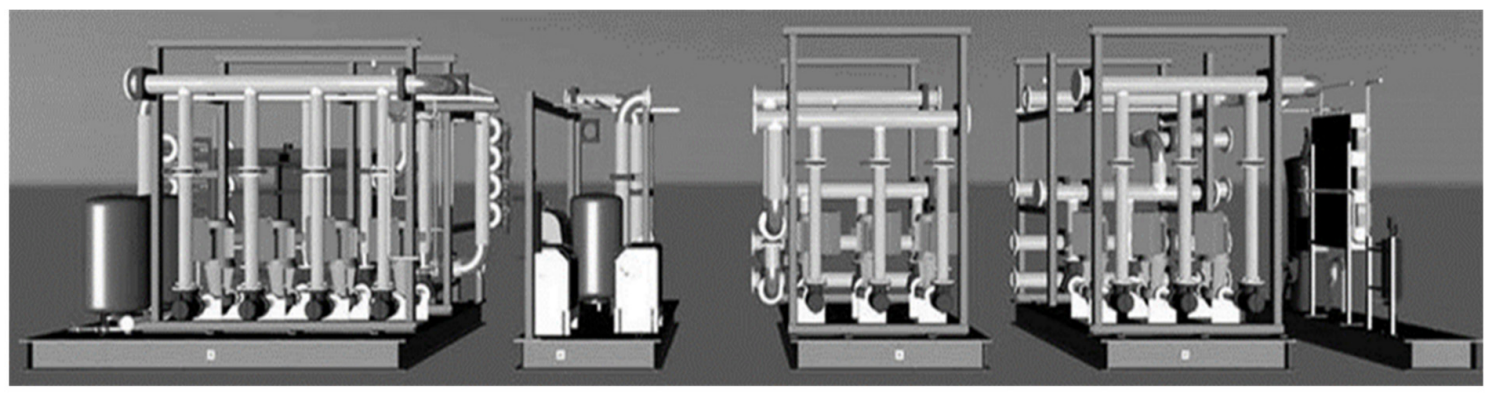

Figure 1. Modular chilled water plant-room (Source: Laing O'Rourke, 2016)

\section{Current approach to designing and framework requirements}

A number of key observations and findings emerged from the analysis of design practices of the collaborating company. They include the following:

- A shift is occurring in its practices from design for on-site to design for off-site construction.

- Requirements are typically captured in project briefs. Instances of more formal and systematic capture and analysis of requirements exist but these are infrequent.

- The approach to modular design is highly iterative and expertise dependent. Modularisation tools to systematically control product variation are not used.

- A product configurator is increasingly seen as useful support to manage designs. However, the product configurator, commonly adopted in industries such as the automotive (Gann, 1996), is still new to the construction industry. The basic functioning of a product configurator, where clients or engineers input product requirements and preferences to drive the selection of modules from a library, is illustrated in Figure 2.

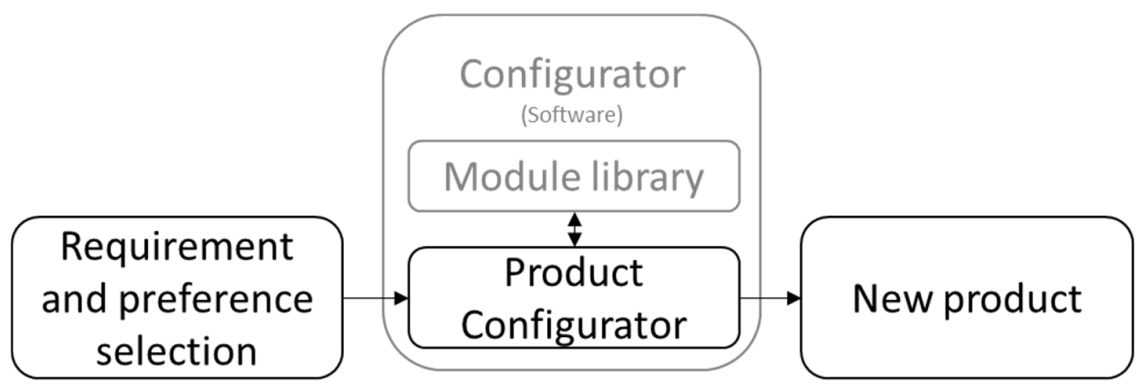

Figure 2. Product configurator 
These findings show that a gap exists between the shift towards off-site construction and the introduction of a product configurator. Specifically, there is a need to support more effective product planning to help define a library of modules. For this purpose a framework to guide engineers in requirements management and product modularisation is required. The specific requirements of the framework are shown in Table 2.

Table 2. Framework requirements

\begin{tabular}{|l|l|}
\hline Requirement & Justification \\
\hline $\begin{array}{l}\text { Guide engineers in } \\
\text { product planning }\end{array}$ & $\begin{array}{l}\text { Product planning is key to achieve mass-customisation and increased } \\
\text { industrialisation. The issues of product quality and product flexibility have to be } \\
\text { solved simultaneously and in an integrated manner. A product planning } \\
\text { framework needs to ensure product quality and flexibility through effective } \\
\text { capture of requirements and definition of product variation. }\end{array}$ \\
\hline $\begin{array}{l}\text { Guide engineers in } \\
\text { requirements analysis } \\
\text { and prioritisation }\end{array}$ & $\begin{array}{l}\text { The construction process involves multiple stakeholders, high levels of } \\
\text { uncertainty and interconnected requirements for new building projects. Guiding } \\
\text { engineers in systematic requirements management practices is crucial to ensure } \\
\text { product quality. }\end{array}$ \\
\hline $\begin{array}{l}\text { Guide engineers in } \\
\text { product modularisation }\end{array}$ & $\begin{array}{l}\text { The construction process involves large product variation, which are a main } \\
\text { source of risk for delivering product flexibility. Guiding engineers in systematic } \\
\text { modularisation practices is crucial to ensure product flexibility. }\end{array}$ \\
\hline $\begin{array}{l}\text { Integrate with a product } \\
\text { configurator }\end{array}$ & $\begin{array}{l}\text { The construction process is shifting towards the automatic definition of product } \\
\text { configurations from existing libraries of product options and the framework has to } \\
\text { support this objective. }\end{array}$ \\
\hline $\begin{array}{l}\text { Support and integrate } \\
\text { with the RIBA process }\end{array}$ & $\begin{array}{l}\text { The construction process is organised and managed by the Royal Institute of } \\
\text { British Architects (RIBA) plan of work and the framework has to fit within this } \\
\text { context. }\end{array}$ \\
\hline
\end{tabular}

\section{The framework}

The framework, consisting of two parts, integrates tools to achieve quality and flexibility in design for mass-customisation (see Figure 3). The first part of the framework looks at requirements management and prioritisation through the utilisation of the QFD tool. The second part looks at product modularisation, which involves utilisation of the DSM, MIM and GVI tools.

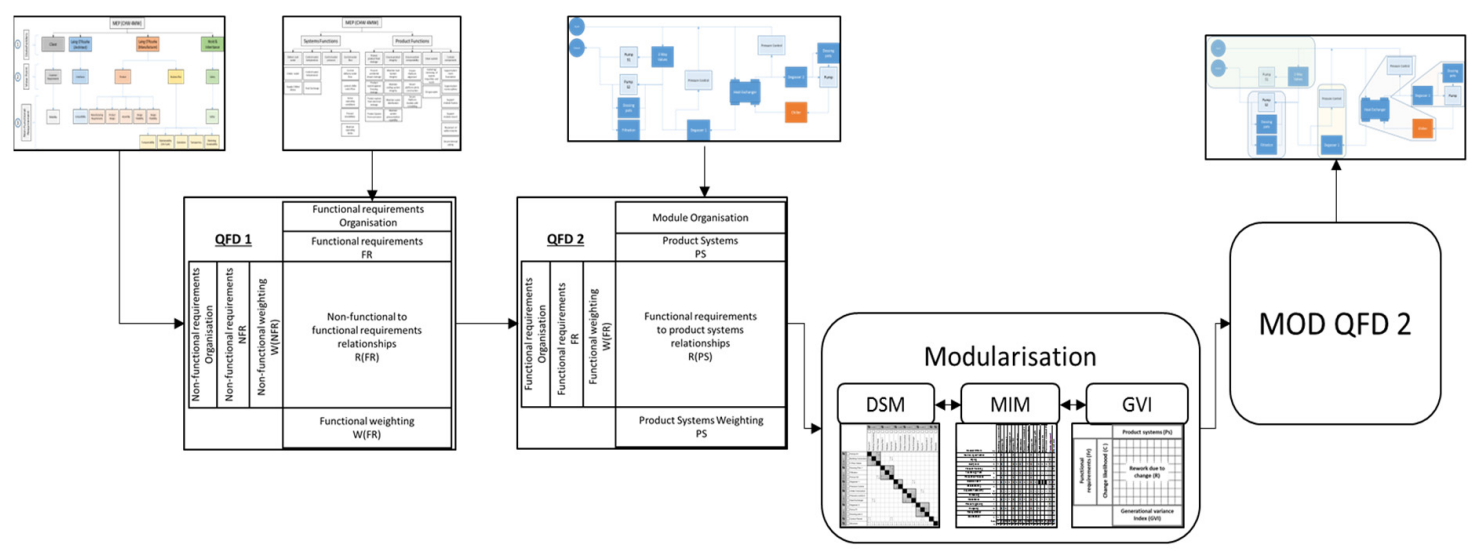

Figure 3. Product planning framework for modular building systems 
Requirements management is important to develop quality modular products. The systematic mapping and organisation of product requirements to product systems is an important prerequisite for modularisation. QFD is employed to facilitate this mapping, which allows systematic development of new products in accordance to the requirements for new product introduction. QFD provides an environment for understanding engineering design rationale across different product representations and their interdependencies. The QFD tool supports the implementation and prioritisation of requirements and product systems. Prioritisation is an important part of the framework as it covers the organisation of product requirements to meet established objectives for mass-customisation. It is useful to understand the shortfall between the current bespoke construction business and the desired mass-customisation outcome. As a result, prioritisation helps identify where it would be best to place a company's resources for higher returns on investment.

Modularisation involves identifying clusters of product components. It helps reduce design risks and increase flexibilities of a product or production system (Koh et al., 2015). A modular problem can derive from a series of different modular drivers. It is important that the correct tools are selected to address the right modular driver. The modularisation aspect of the framework looks at utilising several tools to best address the modularisation problem. These tools include MIM, GVI and DSM. MIM tackles a variety of modular drivers, e.g. technical specification, styling, common unit, purchasing, etc. but without algorithmic foundations. GVI is used to tackle the "common unit" modular driver. DSM often tackles the "technical specifications" modular driver (Wee et al., 2017b). When the correct tools for the problem are utilised the modularisation problem can be solved adequately. This allows for more effective modules to be developed which reduces the amount of effort needed for redesign.

DSM is a method that maps systems interdependencies in matrix form. It is used in systems engineering and project management to model and analyse complex systems. The matrix maps the dependencies between complex systems and subsystems (Hölttä-Otto 2005; Borjesson, 2010; Jung, 2016). DSM clusters product systems based on systems dependencies, and addresses the "technical specifications" modular driver with a technical solution. It also considers "maintenance" issues but not robustly. Concentration of high dependency amongst product systems signifies that the systems have higher functional reliance on each other. Therefore, it would be beneficial if they were clustered together into a module. This would allow the module to hold a section of the product's functionality and addresses "technical specification" modular driver (Wee et al., 2017b).

MIM is a QFD-like tool that is used to identify which technical solutions should be clustered into modules (Erixon, 1996; Borjesson, 2010). It maps modular drivers against technical solutions. The matrix layout provides a visualisation of the interrelationships between modular drivers and technical solutions, which supports the implementation of modularisation rationale in accordance to the modular drivers (Erixon, 1996; Borjesson, 2010). MIM has a more holistic approach on modularity and supports a wider scope of modular drivers associated with construction. It offers a platform for determining how the various modular drivers interact with one another. However, it lacks technical rigor and relies heavily on human rational and judgment in determining modules (Wee et al., 2017b).

GVI is a tool that has been used for development of modular product platforms. It supports the identification of product components, which are less likely to require redesign (Simpson, 2004; Jiao et al., 2007; Simpson et al., 2012). The tool takes advantage of the occurrence of core functional requirements that reoccurs across multiple products to develop a common product platform. GVI is a metric tool that approximates the likelihood and potential rework needed for the next product evolution. It directly targets the "technology evolution" modular driver. GVI can also be used as a standardisation indicator and to address the "common unit" modular driver. The development of "common unit" relates to the collection of product systems, which are least likely to change. As such, it supports the development of a product platform. 


\section{Application of the framework}

\subsection{Requirements management}

Product planning was supported through the QFD tool, which can capture and analyse requirements arising from multiple disciplines. The QFD tool was applied using a functional approach. Figure 4 illustrates the overall structure of the QFD framework including QFD1 and QFD2 matrices applied to the plant-room case study.

In the product development process, it is important that the concerns of each stakeholder are accounted for as much as possible from the early stages of design. This includes understanding both the nonfunctional requirements (NFR) and functional requirements (FR). For example, the non-functional requirements of a plant-room can be organised in a hierarchal structure, which takes into account the concerns of stakeholders (Wee et al., 2017a). The stakeholders were associated with their primary 'product viewpoints', which were then broken down to form individual requirements groups. The functional requirements were organised into primary and secondary functions (Wee et al., 2017a).

The QFD model developed in this research consists of 40 non-functional requirements, 29 functional requirements and 18 product systems. QFD1 and QFD2 include 337 and 79 relationships respectively. The details of the QFD model are described in Wee et al. (2017a).
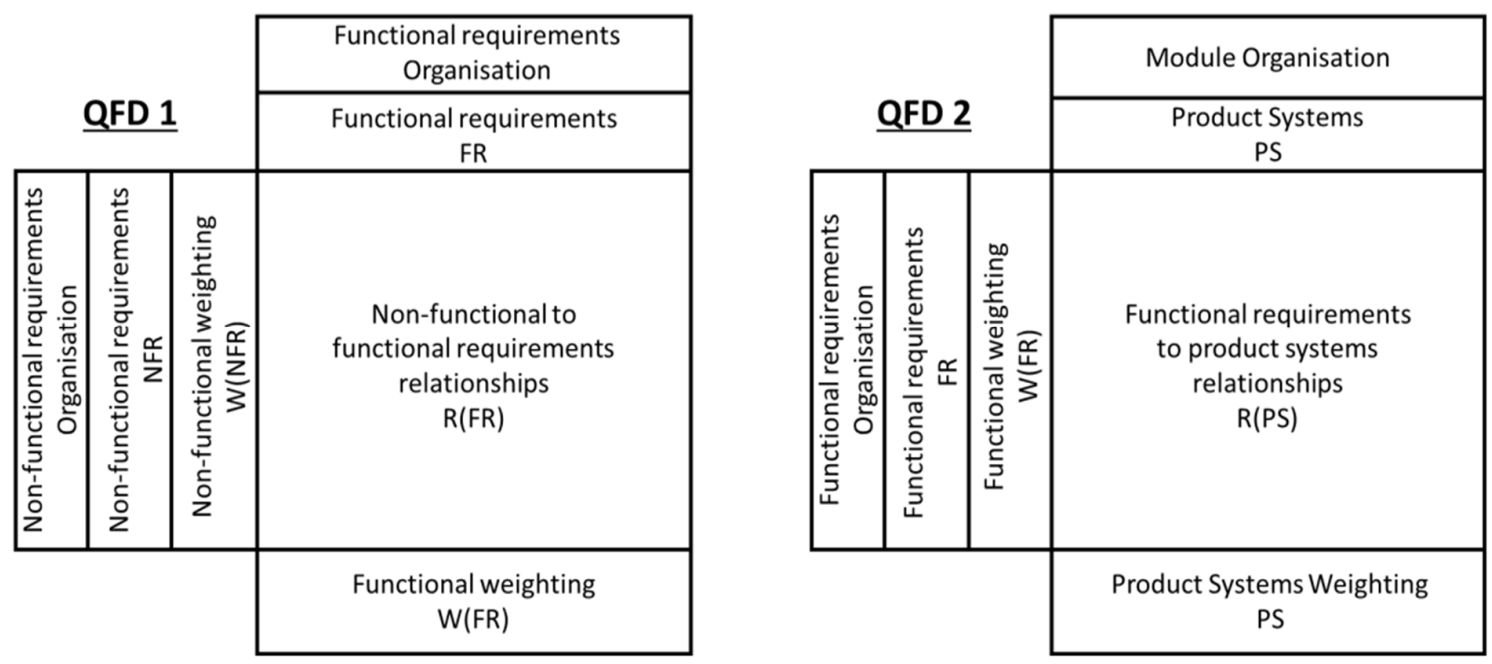

Figure 4. Lay out of QFD1 and QFD2 (Wee et al., 2017a)

Figure 5 highlights the importance of the functional requirements of the plant-room, which is dependent on the non-functional requirements and was calculated based on QFD1. The non-functional requirements elicited in this research are characteristic of advanced modular off-site construction. A subset of the non-functional requirements are in common with bespoke construction, while the remaining non-functional requirements are what is needed to shift from bespoke to mass-customisation through modular off-site construction. The difference between the non-functional requirements in bespoke and off-site construction projects influence the importance of the functional requirements. As it can be seen in Figure 5, a shortfall exists between the functions of a bespoke and off-site construction project and there is a need to give attention to the functions related to structural components, as they are more likely to yield higher potential result in the shift to off-site construction. The shortfall is due to certain non-functional requirements (i.e. ease of manufacturing, ease of assembly, design flexibility and transportation) being mainly satisfied by structural components, and they do not normally exist in traditional bespoke construction. 


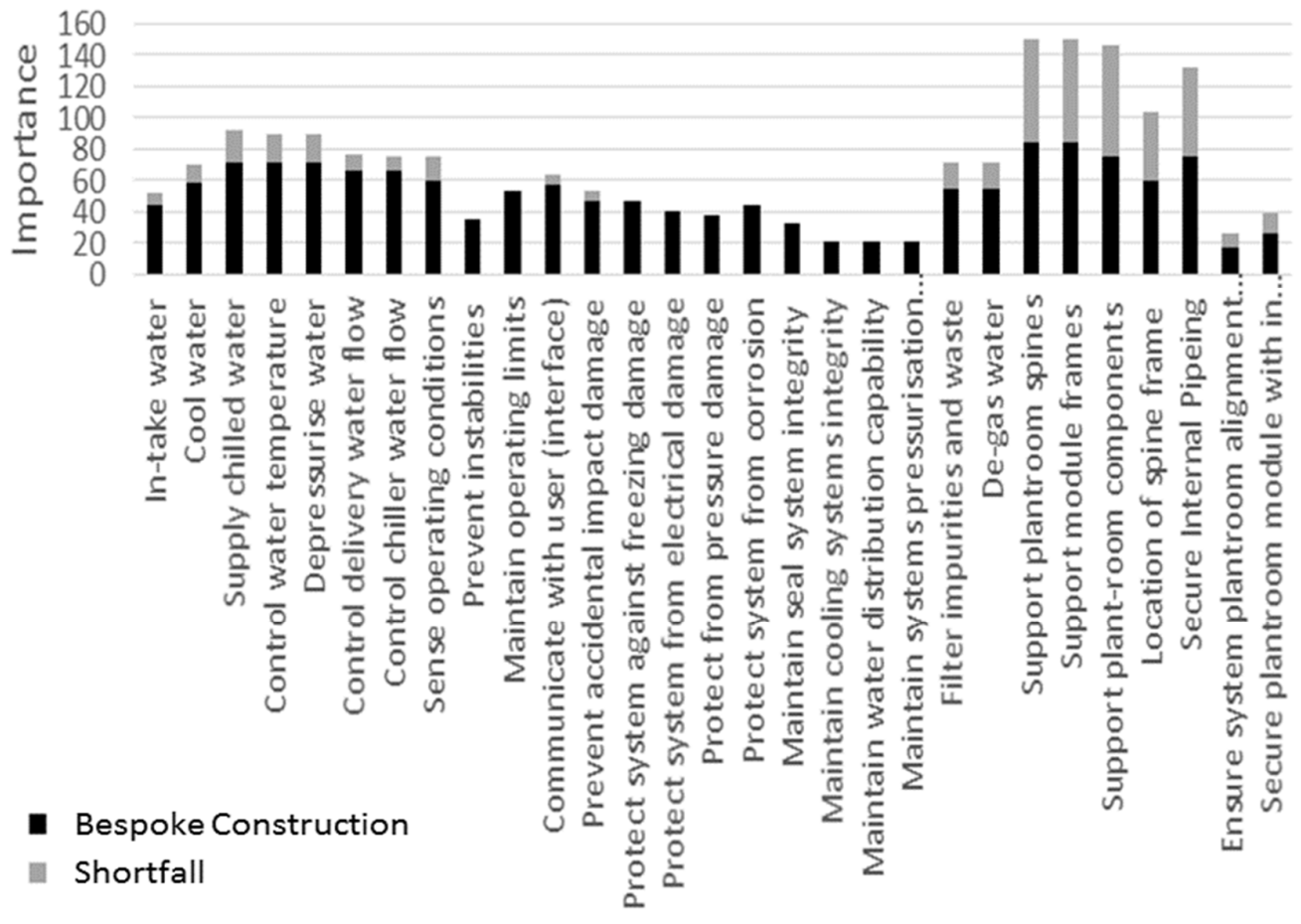

Figure 5. Prioritisation analysis

\subsection{Modularisation}

Mass-customisation in construction is influenced by multiple drivers. These have to be addressed simultaneously and multiple tools are needed to capture the full complexity of a modularisation problem. This research recommends the integration of complementary tools to generate more effective modular solutions. The utilisation of a data driven design process allows for a more insightful design analysis to support the definition of modular products. It allows for the identification of possible design advantages by tackling individual modular drivers. For example, the identification of dependency concentration (e.g. technical specification) allows to ease design management and the utilisation of indices to address specific design objectives.

Modularisation was supported through the DSM, MIM and GVI tools (see Figure 6). The modularisation rationale was developed by understanding and prioritising the modular drivers and corroborated by the DSM, MIM and GVI tools. DSM, MIM and GVI were explored to support an algorithmic approach to modularisation (Wee et al., 2017b). DSM is a dependency component based tool, which is good at capturing the "technical specification" modular driver. MIM best addresses trade-off between multiple modular drivers and interdisciplinary considerations. Finally, GVI was used for the development of product platforms.

Using the DSM, MIM and GVI tools, modular tool matrices were developed as detailed in Wee et al. (2017b). All three matrices were applied to the same plant-room product involving 16 product subsystems. DSM consists of a $16 \times 16$ matrix, MIM mapped 15 modular drivers against the 16 product sub-systems, and the GVI was generated from QFD2 (which maps 29 product requirements versus 18 product systems).

The DSM based solution is more closely aligned with the current modularisation objectives covered by the design engineers at the collaborating company (i.e. functional dependency between the product subsystems). MIM comes in a close second, followed by GVI.

This research compared three modularisation tools applied to support the design of a plant-room. The three tools were evaluated by determining their effectiveness in addressing modular drivers. Fifteen 
modular drivers were identified and prioritised (see Wee et al., 2017a). Each of the three tools addresses a different set of modular drivers and with a process that is either algorithmic or judgement based. MIM offers a more holistic approach to modularisation and supports a wider range of modular drivers. However, it lacks technical rigor in determining modules. DSM and GVI provide technical solutions but each of them focuses on specific modular drivers, namely DSM on "technical specification" and GVI on "common unit" and "technology evolution".
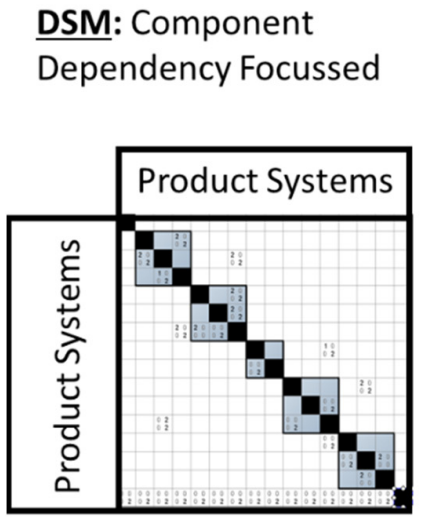

MIM: Business Strategy Focussed

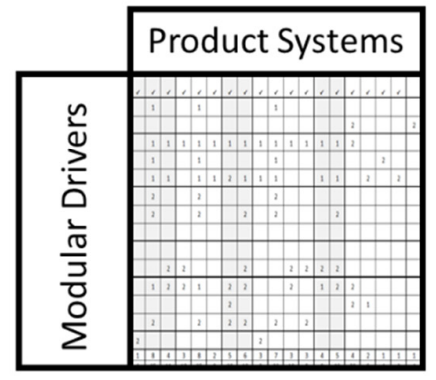

\section{Product Platforms with GVI: Product Variance Focussed}

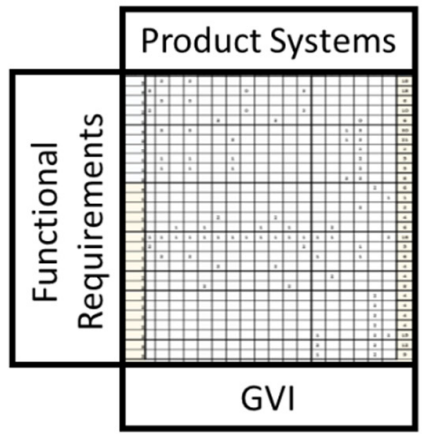

Figure 6. Modularisation tools explored to support modularisation rationale (Wee et al., 2017b)

Combining the results from multiple drivers provides valuable design information to support the development of a modular product. The results can then be integrated to form a singular modularisation solution that accommodates several modular drivers.

\section{Evaluation}

A workshop attended by eight engineers established that the QFD model is useful and in-line with the business vision of the collaborating company (Wee et al., 2017a). Positive feedback on the application of QFD in advanced offsite construction was received from the participants to the workshop. There are two important findings from the evaluation. First, the implementation of a functional approach to QFD and the hierarchical organisation of its elements seem to lead to a more robust and in-depth understanding of requirements. In particular, the method of using QFD proposed in this research was found to capture engineering experience by allowing the design of next generation products to be less reliant on expert engineers. Second, the prioritisation system for functional requirements seems to be a valuable feature of the QFD model. This is because the model helps identify issues of importance in advanced offsite construction. This feature is crucial for efficient allocation of resources and investments.

The evaluation of the modularisation work suggested that the MIM based design is distinctively closer to the company design compared to those produced with DSM and GVI. On the other hand, the MIM tool can help identify the best trade-off between multiple modular drivers and it takes into account interdisciplinary considerations including additional information requirements (Wee et al., 2017b).

\section{Discussion}

A limited number of past studies has applied modular product planning frameworks to construction projects (Veenstra et al., 2006; Gilbert III et al., 2013). However, these studies have employed methods from other research fields that were not specifically adapted for construction. The framework 
proposed in this paper takes a more tailored structure to address mass-customisation in construction. It provides a comprehensive and advanced tools system to analyse requirements and propose modular designs. It specifically uses a functional approach to QFD to introduce more rigour in the way requirements are organised and analysed compared to QFD applications in (Veenstra et al., 2006; Gilbert III et al., 2013). It also suggests how to formulate modular solutions by tackling multiple drivers relevant to the specific problem at hand (e.g. technical specification and common unit). Overall, the proposed framework is expected to support a deeper understanding of product planning for mass-customisation in construction than those proposed in existing literature (Veenstra et al., 2006; Gilbert III et al., 2013).

The QFD model increases understanding of how non-functional requirements, functional requirements and product systems can be interconnected. It shows how product requirements and product systems can be hierarchically organised. In addition, the QFD model allows for the visualisation of the impact of mass-customisation and advanced manufacturing issues such as ease of manufacturing and assembly, design flexibility, and transportation on functional requirements and product systems. Another important benefit of the model is its potential to increase efficiency in product planning through the application of the prioritisation mechanism. This can be especially useful for the construction industry to move towards mass-customisation and advanced manufacturing environment. The prioritisation feature of the QFD model was received positively, as it can support and direct design efforts in a more efficient manner.

Modularisation provides design flexibility and is an effective solution to achieve mass-customisation. Design flexibility is key to adapt designs to changing situations. In this research three tools to tackle modular drivers and the process to produce a modular solution (i.e. algorithmic or judgement-based process) are applied. The research brings out the importance of addressing the modularisation problem by considering its modular drivers. This indicates that several modular drivers need to be tackled simultaneously and the solutions integrated.

\section{Conclusions}

This research describes the problem of developing product planning tools for mass-customisation in the construction industry. A product planning framework was proposed to tackle this problem. The framework achieves this through the implementation of methods for requirements management and modularisation. A plant-room case study was used to evaluate the framework by applying the tools and exposing the models to engineers in the collaborating company. The results demonstrate operation and applicability of the framework.

This research highlights the potential benefits of QFD as a requirements analysis tool for advanced offsite construction. The QFD model allows for a more holistic and systematic approach to requirements analysis than current practices at the collaborating company and previous applications of the tool in construction. The research also provides insights into the modularisation rationale needed to address mass-customisation. DSM, MIM and GVI tools emerge as valuable tools, which support different modular drivers. A combination of tools is needed to address any given situation with the aim to generate algorithmic robustness and a spectrum of modular drivers.

\section{Acknowledgments}

The authors acknowledge the support for this research from the EPSRC and Laing O'Rourke through iCASE number $\mathrm{N}: 1589417$.

\section{Reference}

Borjesson, F. (2010), "A systematic qualitative comparison of five approaches to modularity", Proceedings of DESIGN $2010 /$ the $11^{\text {th }}$ International Design Conference, Dubrovnik, Croatia, The Design Society, Glasgow, pp. 147-156.

Emmatty, F.J. and Sarmah, S.P. (2012), "Modular product development through platform-based design and

DFMA", Journal of Engineering Design, Vol. 23 No. 9, pp. 696-714.

https://doi.org/10.1080/09544828.2011.653330 
Erixon, G. (1996), "Modular function development MFD, support for good product structure creation", Proceedings of the $2^{\text {nd }}$ WDK Workshop on Product Structuring, Delft University of Technology, the Netherlands, June 3-4, 1996, The Design Society, Glasgow.

Gann, D.M. (1996), "Construction as a manufacturing process? Similarities and differences between industrialized housing and car production in Japan", Construction Management and Economics, Vol. 14 No. 5, pp. 437-450. https://doi.org/10.1080/014461996373304

Gilbert III, L.R., Farid, A.M. and Omar, M. (2013), "An Axiomatic Design-Based Approach to Civil Engineering", Proceedings of the $2^{\text {nd }}$ International Workshop on Design in Civil and Environmental Engineering, DCEE, Worcester, MA, p. 30-38.

Gilbert III, L.R., Omar, M. and Farid, A.M. (2014), “An integrated QFD and axiomatic design methodology for the satisfaction of temporary housing stakeholders", Proceedings of ICAD2014 / the $8^{\text {th }}$ International Conference on Axiomatic Design, Campus de Caparica, September 24-26, 2014.

Hölttä-Otto, K. (2005), Modular product platform design, PhD thesis, Helsinki University of Technology.

Höök, M. (2006), "Customer value in lean prefabrication of housing considering both construction and manufacturing", Proceedings of the 14th Annual Conference of the International Group for Lean Construction, Santiago de Chile, pp. 583-594. htttps://doi.org/10.1061/9780784413616.132

Jensen, P., Olofsson, T., Smiding, E. and Gerth, R. (2014), "Developing Products in Product Platforms in the AEC Industry", Proceedings of the International Conference on Computing in Civil and Building Engineering, Orlando, USA, June 23-25, 2014, ASCE, pp. 10621069. https://doi.org/10.1061/9780784413616.132

Koh, E., Förg, A., Kreimeyer, M. and Lienkamp, M. (2015), "Using engineering change forecast to prioritise component modularisation", Research in Engineering Design, Vol. 26 No. 4, pp. 337-353. https://doi.org/10.1007/s00163-015-0200-5

KPMG (2016), Smart construction: how offsite manufacturing can transform our industry, KPMG.

Lawson, R.M., Ogden, R.G. and Bergin, R. (2012), "Application of modular construction in high-rise buildings", Journal of architectural engineering, Vol. 18 No. 2, pp. 148-154. https://doi.org/10.1061/(ASCE)AE.1943-5568.0000057

Marchesi, M. and Ferrarato, I.A. (2015), "Addressing the adaptive customization of timber prefabricated housing through axiomatic design", Procedia CIRP, Vol. 34, pp. 199-205. https://doi.org/10.1016/j.procir.2015.05.001

Marchesi, M., Kim, S.G. and Matt, D.T. (2013), "Application of the axiomatic design approach to the design of architectural systems: a literature review", Proceedings of ICAD2013 / the $7^{\text {th }}$ International Conference on Axiomatic Design, Worchester, June 27-28, 2013, ICAD, pp. 27-28.

Martin, M.V. and Ishii, K. (2002), "Design for variety: developing standardized and modularized product platform architectures", Research in Engineering Design, Vol. 13 No. 4, pp. 213-235. https://doi.org/10.1007/s00163-002-0020-2

Sellgren, U. and Andersson, S. (2005), "The concept of functional surfaces as carriers of interactive properties", Proceedings of the ICED'05 / $15^{\text {th }}$ International Conference on Engineering Design, Melbourne, Australia, August 15-18, 2005, The Design Society, Glasgow.

Simpson, T.W. (2004), "Product platform design and customization: Status and promise", Artificial Intelligence for Engineering Design, Analysis and Manufacturing, Vol. 18 No. 1, pp. 3-20. https://doi.org/10.1017/S0890060404040028

Simpson, T.W., Bobuk, A., Slingerland, L.A., Brennan, S., Logan, D. and Reichard, K. (2012), "From user requirements to commonality specifications: an integrated approach to product family design", Research in Engineering Design, Vol. 23 No. 2, pp. 141-153. https://doi.org/10.1007/s00163-011-0119-4

Simpson, T.W., Siddique, Z. and Jiao, R.J. (2006), Product platform and product family design: methods and applications, Springer Science and Business Media, Boston, USA. https://doi.org/10.1007/0-387-29197-0

Ulrich, K.T. and Eppinger, S.D. (2008), Product design and development, MacGraw-Hill, NewYork.

Veenstra, V.S., Halman, J.I.M. and Voordijk, J.T. (2006), "A methodology for developing product platforms in the specific setting of the housebuilding industry", Research in engineering design, Vol. 17 No. 3, pp. 157173. https://doi.org/10.1007/s00163-006-0022-6 
Wee, T.P.Y., Aurisicchio, M. and Starzyk, I. (2017a), "The application of quality functional deployment to modular offsite construction products", Proceedings of ICED'17 / the $21^{\text {st }}$ International Conference on Engineering Design, Vol. 4, Vancouver, Canada, August 21-25, 2017, The Design Society, Glasgow, pp. 523-532.

Wee, T.P.Y., Aurisicchio, M. and Starzyk, I. (2017b), "Evaluating modularisation tools in construction", Proceedings of the 34rd ISARC International Symposium on Automation and Robotics in Construction, Vol. 34, Taipei, Taiwan, IAARC, pp. 325-332. https://doi.org/10.22260/ISARC2017/0044

Tanawan P. Y. Wee Imperial College London, Dyson School of Design Engineering 10 Princes Gardens, Kensington, SW7 2AZ London, United Kingdom Email: t.wee15@imperial.ac.uk 